\title{
Sisterhood and affective politics: The CaiRollers mobilising change through roller derby in Egypt
}

\begin{abstract}
This article narrates the affects and experiences of the CaiRollers, the first and only roller derby team in Egypt. Through visual affective discourse analysis of their Instagram account and interviews with team members, the article addresses the question: What do physical practices such as roller derby 'do' in e/affecting and mobilising change? In conversation with feminisms from the Middle East, our analysis highlights how the team's 'sisterhood' is a site of affective politics that transcends the roller derby track. At the same time, a desire to be tough and to embrace risk permeated the CaiRollers discourses. Yet, while the team has established its legitimacy within the transnational roller derby community, we narrate the obstacles they face in Egypt. In sum, we found that the CaiRollers involvement in roller derby was entangled in mobilising change in political movements, gender politics, transnational mobilities and questions of legitimacy and sport.
\end{abstract}

Keywords: visual affective discourse analysis, roller derby, Middle Eastern feminisms, risk, feminism, affect, sport, gender politics, social media 


\section{Sisterhood and affective politics: The CaiRollers mobilising change through roller derby in Egypt}

Roller derby is a physical, cultural, and creative practice that originated in the United States, before spreading across the globe, aided and mediated through digital technology. It is a contact sport played on roller skates and led predominately by women. Through actively resisting incorporation into traditional sport structures (Finley, 2010), roller derby challenges dominant constructions of sport and sportswomen. At the heart of roller derby is a persistent 'DIY' ethos, expressed by the mantra, 'by the skaters, for the skaters' (Beaver, 2012: 25), which both enables and restricts roller derby to reach and e/affect a broad range of people. This article focuses on roller derby in the Middle East and North African region, specifically Egypt, through narrating the experiences of the country's first roller derby team: the CaiRollers. We use visual affective discourse analysis of the CaiRollers Instagram account and interviews with current league members to interrogate roller derby and draw on affect and feminisms, centring on those emerging from the Middle East.

We follow Abu-Lughod's (1991, 2013, 2019; Lutz and Abu-Lughod, 1990) and Ahmed's (2004) works which invite us to attend to the role of power in the politics of emotions and representation in order to decentre Western narratives and feminisms that continue to reproduce Orientalist tropes. In doing so, we pay attention to the CaiRollers women's desires, politics and how their involvement in roller derby embodies strength, toughness, and sisterhood. The CaiRollers embodied and affective narratives bring to the fore important questions of power and politics, and discourse and representation from a Global South and Middle Eastern episteme. Increasingly sportswomen are challenging heteronormativity and sexism in sport, but there is still a need to critically understand and dismantle racism and white privilege in women's sport (Cardoso Brown, 2018; Pavlidis, Rodriguez Castro and Kennelly, 2020; Ratna, 2018). In this respect, Abu-Lughod (2013: 6) argues that 'generalizing about cultures prevents us from appreciating or even accounting for people's experiences and the contingencies with which we all live' and calls for 'writing against culture'.

Abu-Lughod's (1991) body of work on 'writing against culture' provides three strategies that we found important for doing cultural studies from this epistemic standpoint. These strategies are: i) discourse and practice, ii) connections, and iii) ethnographies of the particular. On discourse and practice, Abu-Lughod (1991: 472) notes that these theoretical and conceptual tools help with, 'recognizing within a social group the play of multiple, shifting, and competing statements with practical effects'. Her second strategy, connections, focuses on reorienting the subject matter of the problem addressed, following, 'national and transnational connections of people, cultural forms, media, techniques, and commodities' (Abu-Lughod, 1991: 473). Her final strategy, ethnographies of the particular, emphasises the specific, rather than seeking generalisability. This is not a turn away from macro processes and power structures, but instead an attempt to better convey the manifestations of 'local and long-term processes'... 'produced in the actions of individuals living their particular lives, inscribed in their bodies and their words' (Abu-Lughod, 1991: 474). Following these strategies to 'write against culture' in this article we ask, what do physical practices such as roller derby 'do' in e/affecting and mobilising change? We use 'e/affect' as a way of representing the embodied politics of social change. Put another way, we argue that the affects of power - things like shame, pride, love, disappointment, excitement and more - have material effects on the social world around us. 
In the next section we present our conceptual framework. First, we introduce important debates on feminisms from the Middle East, making connections to the literature on sport, roller derby and feminisms. Based on these debates, we then focus on affect through reviewing literature that explores what the politics of emotion do in sport and social media. Next, we present our methodology and findings. Our findings speak to the affective politics of the CaiRollers through three themes: their 'desire to be tough', the team's affective politics of love and 'sisterhood', and the challenges and opportunities of roller derby as a transnational sport. In the conclusion we return to the question: What do physical practices such as roller derby 'do' in e/affecting and mobilising change?

\section{Conceptual framework}

\section{'Writing against culture', sport and feminisms}

Sportswomen from the Global South are often represented through a deficit discourse wherein their 'inclusion' in sport is interpreted through Western constructions of sport participation (see Amara, 2012; Burnett, 2015; Dosekun, 2015; Thorpe 2020; Thorpe and Ahmad, 2015; Pavlidis and O'Brien, 2017; Toffoleti and Palmer, 2017). This is particularly evident in Sport-forDevelopment initiatives which have failed to engage critically with the role of northern subjectivities and which continue to reproduce inequalities in localities in the Global South (see Thorpe, 2020: 4; Burnett, 2015). Toffoletti and Palmer's (2017: 147) survey of literature on Muslim women's' sporting participation suggests a need to move 'beyond a deficit view of Muslim women's sports participation, which is typically couched in terms of barriers to social inclusion through sport'. Attending to these issues, we turn our focus to feminisms and scholarly work emerging from Middle Eastern epistemes.

In the narratives of the CaiRollers we found connections to feminisms and scholarly work from the Middle East that has argued for the importance of centering the everyday experiences of Middle Eastern women (Abu-Lughod, 1998, 2013; Altorki and El-Solh, 1988; Glas and Alexander, 2020; Ahmad and Thorpe, 2020). This is particularly important in light of debates that contend that mainstream transnational feminist and post-feminist debates continue to other, homogenise and essentialise the diverse experiences of Middle Eastern women (Abu-Lughod 1991, 2013, 2020; Dosekun, 2015; Glas and Alexander, 2020; Thorpe and Ahmad, 2015; Samie and Toffoletti, 2018; Ahmad and Thorpe, 2020). Samie and Tofffoletti (2018: 88) illustrate these debates based on their analysis of Muslim sportswomen's representations in the US and argue that 'recognising that the co-existence of competing discourses to make sense of Muslim women often results in essentialist derogatory rhetoric being both disrupted and reinforced at the same time'. This observation is rooted in an issue that Abu-Lughod (1998) and postcolonial scholars have debated over three decades, which is the need to refuse the socioculturally constructed divide between 'Eastern tradition' and 'Western modernity'. Abu-Lughod (2013: 6) addresses the critiques to these Orientalist traditions and calls for 'writing against culture'. Based on Said's (1978) book Orientalism, Abu-Lughod's (2019: 38) comments that it is also important:

to ask not just about representations (or "misrepresentations") of people in the region but [also about] the power/knowledge nexus of these representations. What work do these representations do? Some tropes seem surprisingly enduring, but we need to look more closely. Are they? 
Roller derby is a rich context through which to ask these questions. What work do representations of derby grrrls do? The following section attends to this question.

\section{Roller derby and feminisms}

Finley's (2010) ethnographic study on roller derby in the United States is one of the most widely cited works on the sport. This study theorises intragender relationships and unpacks the complexity of 'alternative femininities' and 'pariah femininities' observed in derby. Through gender manoeuvring (that is, disrupting the 'rules' of gender) Finley (2010: 360) sees the potential for sports like roller derby to 'threaten the inequality of gender relations', yet is cautious in her claims. Finley demonstrates the ways women in derby are not seeking to abandon femininity, but to appropriate/incorporate pariah identities. As she writes, 'skulls and crossbones have pink bows' (Finley, 2010: 372). A number of other have taken up this theoretical and conceptual trajectory - that is, notions of hegemonic masculinity and emphasised femininity for understanding and researching roller derby (see Carlson, 2010 for another notable example).

A concurrent body of work on roller derby has taken a different feminist trajectory, drawing on feminist post-structuralism and conceptualisations of affect and emotion to move beyond representation. This work has asked what affect and representations do? We argue that this feminist approach is more aligned with Abu Lughod's strategies for writing against culture. Key authors include Breeze $(2013,2014)$, and Pavlidis and Fullagar (2014a) who work to 'open up the subject' (St Pierre, 2001: 143) using different theoretical trajectories and concepts, such as organisation and affect. Breeze (2013: 21) focuses on 'roller derby's gendered relation to the broader sport field' and embraces ambivalence in her analysis of the sport and of the skaters she engaged. The complexity and contradictions in a sport which draws so explicitly on humour (through parody, fantasy, irony), aggression (as a contact sport), fitness and skill at local and national levels requires more than an understanding of the ways femininity has been emphasised or changed, but rather a focus on relationality, and practice. Breeze (2014: 157) conceptualises 'non-/seriousness' as a theoretical tool for opening up the agency/structure binary.

Pavlidis' work on roller derby (alone and with Fullagar) has a similar goal of intervening in the structure/agency binary, primarily drawing on feminist theorisations of affect and emotion (e.g. 2014a; 2015; 2017). Conceptualising affect and emotion as both cognitive and nonrepresentational, she incorporates Deleuze and Guattari's writing along with feminist scholars such as Bradotti and Ahmed to reveal the gendered power relations between women, and between roller derby and the field of sport. As sport scholar Markula notes, Deleuze and Guattari's (1987) writing provides 'imaginary ways of looking at bodily identity... divorced from the feminine-masculine dichotomy' (2006: 32). Pavlidis and Fullagar (2013: 678) write:

The women involved in roller derby are not imitating 'being a roller derby grrrl', nor is there such a thing as a 'natural' derby grrrl, an essential set of qualities that define what woman is. Rather, women who play and post images or text are always becoming-derby grrrl as they produce affects (as distinct from static representations of meaning).

Thus, rather than emphasising femininity or feminine identity, Pavlidis' work shifts to understand the relational aspects between embodiment and sport (specifically roller derby) and representation. For example, through theories of affect they provide an account of the ways aggression and 'hardness' can relate to love, and in some instances healing. Yet also the ways 
love (for the game, for the practice or the identity of 'derby grrrl') can relate to bullying, hate or exclusion. Our engagement with the CaiRollers (both their skaters and social media account) follows this approach through the politics of emotions, while also attempting to 'write against culture' and de-centre whiteness. That is because studies of roller derby that explicitly seek to de-centre whiteness, US-centrism and are written in English are limited, despite the presence of the sport in localities all over the Global South.

\section{Politics of emotion and digital spaces}

Lutz and Abu-Lughod (1990:1) demonstrated the importance of a sociocultural analysis for contesting understandings of emotions as 'tied to tropes of interiority'. In Language and The Politics of Emotion they explained the dangers of 'essentializing emotions' as this goes hand in hand with an invisibility of affect itself, 'since positing emotion universals allow us more easily to take emotion for granted' (Lutz and Abu-Lughod, 1990: 3). Thus, they argued for a crosscultural analysis of emotions that historicised, focused on social discourse and centred discussions about the politics of everyday life in specific geographies. Our focus on exploring the a/effects of roller derby in mobilising change connects to Lutz and Abu-Lughod's (1990:12) argument that 'we should view emotional discourse as a form of social action that creates effects in the world, effects that are read in a culturally informed way by the audience for emotion talk'. This is a shift from meaning to a focus on 'how emotional discourses are implicated in the play of a historically changing system of social hierarchy' (Lutz and Abu-Lughod, 1990: 15). In our current epoch this changing system of social hierarchy is played out as much in digital spaces as in physical spaces.

Nida Ahmad (2020) recently wrote about Muslim women's social media use in sport contexts, providing an important starting point for our later analysis. Ahmad and Thorpe (2020: 670) note that discussions about social media and Muslim activism are mostly associated with the Arab Spring uprisings of 2011. However social media had been embraced by women in the region before then to discuss feminism, religions, gender-based discriminatory laws and politics (Nouraie-Simone, 2014). Ahmad and Thorpe extend Puwar's (2004) concept of space invaders which focused on the ways 'Others' enter into spaces dominated by the bodies of privileged white men, and disrupt the status quo, and in doing so having to constantly reposition themselves within these spaces through embodied rituals. In Ahmad and Thorpe's (2020: 672) exploration of digital practices, they discuss Muslim sportswomen as 'digital space invaders' who are, 'subtly navigating the cultural complexities of their offline and online lives and creatively using digital spaces to offer alternative representations of Muslim sportswomen too long represented as out of place'.

Conceptualising Muslim sportswomen's digital practices through Ahmad and Thorpe's (2020) notion of 'digital space invaders' connects with our understanding of affect and emotion as 'effects rather than origins' (Ahmed, 2004: 196). Emotions and affects can disrupt and influence. As Ahmed (200a4: 196) writes, "emotions are not only about the "impressions left" by others, but ...involve investments in social norms'. Pavlidis and Fullagar (2014a) work interrogates the relationships between social norms in derby and emotions, and the ways 'toughness' can be mobilised (online and off) to disrupt, and sometimes adhere to, gender norms. In particular, the digital context of roller derby - as a sport reinvented in the contemporary era of new digital media (Pavlidis and Fullagar, 2014b) - creates opportunities for visibility and affecting others. Drawing on Ahmed's work, Pavlidis and Fullagar (2013: 682) write, 'the virtual 
space of derby culture is claimed through enjoyment that is 'witnessed' by others (Ahmed, 2004c). Those who show the most enjoyment, the most pleasure - those who love roller derby the most - are the most entitled'. Emotions 'matter' for politics - whether it be micro politics as with roller derby communities, or macro global politics, 'emotions show us how power shapes the very surface of bodies as well as worlds' (Ahmed, 2004: 12). Emotion and affect are a form of world making, which, as we demonstrate in our analysis below, the CaiRollers have taken up as a way of invading 'digital' spaces and making change.

\section{Methodology}

\section{Background to the study: The CaiRollers and roller derby in Egypt}

The CaiRollers, 'the first and only roller derby team in Egypt', were founded in 2012 by two women teaching at a local international school, one from the United States and one from the United Kingdom (CaiRollers, n.d.). The team comprises 'skaters of Egyptian nationalities, dualcitizenships, and ex-pats, [with] different belief systems and various professions and backgrounds' (CaiRollers, n.d.). In their inaugural year, the CaiRollers struggled to gain access to equipment and a suitable venue (Egyptian Streets, 2014). While these structural constraints have resolved over time, since their inception, the CaiRollers have also tackled recruitment challenges in a bid to sustain adequate local competition. The team epitomise the DIY ethos of roller derby in that they do not have a coach. Instead, they use YouTube and other social media channels to connect with international coaches for ideas on training and strategy. 'Female camaraderie' (Gbadamosi, 2017: n.p.) has been critical to maintaining the team. In a 2018 news article, the CaiRoller Noha Eid described the team as 'like a sisterhood' which had opened up 'a worldwide network' for players through the international roller derby community (United Nations Women, 2018: n.p.).

The CaiRollers were founded at a time of profound socio-political change in Egypt and the Arab world. The Arab Spring uprisings were 'collective actions', led by youth and catalysed by poor governance, injustice, inequality, censorship, and repression (Mohamed, Mahdi and Dabashi, 2020: 142). The scholarship surrounding the Arab Spring discusses two themes of relevance to the current paper: the political and cultural awakening that ran concurrent with the uprisings, and the central role of digital technologies and cyberactivism in communicating 'inside stories'. In the aftermath of the uprisings, Biagini (2020: 399) found that a generation of young women who participated in the 'revolutionary struggle and the subsequent repression of Islamists fostered the development of a gendered awareness that has resulted in these women's adoption of a new gender politics' with 'feminist overtones'. The uprisings created a climate in which less-traditional forms of self-expression (i.e., street art, rap) developed and reached new audiences through the use of social media (Mohamed, Mahdi and Dabashi, 2020). In particular, Walsh (2017: n.p.) commented that the political uprisings catalysed Egyptians to embrace 'new forms of cultural expression... and unconventional sports like roller derby'.

\section{Visual affective discourse analysis}

This paper draws on visual affective discourse analysis of the CaiRoller's Instagram account (@cairollers), supported by three qualitative interviews with team members. Visual discourse 
analysis is a methodology that facilitates an understanding of how discourse is articulated in both images and text, with a focus on questioning power rather than seeking 'truths' (Leeuwen and Jewitt, 2001; Rose, 2001). We were particularly interested in how the visual and textual discourse of the CaiRollers' Instagram posts constructed affective, everyday and embodied understandings of sport as an important realm of the social world. Hence, through our analysis we sought to reveal the (visual) affective-discursive practices privileged by the CaiRollers.

Our visual affective discourse analysis of the Cairollers' Instagram posts involved analysis of 75 images (and associated captions) from a twelve-month period (March 2018 March 2019). The 75 images were entered into a spreadsheet which identified points of interest (i.e. whether images were active/passive and/or collective/individual, aesthetics, clothing and other 'messaging') which were then interrogated by the research team. Following Wetherell's (2013) discussion of affective discursive practices, we specifically reflected on how affect and bodies construct the CaiRollers' discourses (see also Pavlidis, Rodriguez Castro and Kennelly, 2020).

In addition, we interviewed three members of the CaiRollers team, as summarised in Table 1. The inclusion of interviews was in answer to Ahmad and Thorpe's (2020) call for research which better captures the voices of sportswomen and their unique forms of agency embedded within complex and often subtle negotiations of self-representation. These interviews covered topics such as how interviewees became involved in roller derby, how they thought roller derby was perceived in Egypt, how they were trying to grow their league, challenges the team had faced, their family and friends' relationship to the team, how they conceptualised the relationship between women's empowerment and playing roller derby, and their use of social media, particularly Instagram.

Table I. Interview participants' information.

\begin{tabular}{lllll}
\hline Participants & $\begin{array}{l}\text { Interview date/ } \\
\text { form }\end{array}$ & $\begin{array}{l}\text { Country of } \\
\text { origin }\end{array}$ & $\begin{array}{l}\text { Years on the team } \\
\text { at time of interview }\end{array}$ & Role on the team \\
\hline Respondent I & 2018 , via Skype & Egypt & 3 years & Skater \\
Respondent 2 & 2018, via email & Egypt & 2 years & Skater \\
Respondent 3 & 2020 , via email & Egypt & 7 years & $\begin{array}{l}\text { Skater; in charge of } \\
\text { team's communication } \\
\text { and social media }\end{array}$ \\
\hline
\end{tabular}

During the analysis process the research team looked for themes across both the visual data (Instagram posts and captions) and interview data (see Rose, 2001; Olive, 2013; Pavlidis, Kennelly and Rodriguez Castro 2020; Pavlidis, Rodriguez Castro and Kennelly, 2020). In particular, by reading across both forms of data we sought to explore affect and embodiment through deeply reflecting on how bodies are self-represented (see Olive, 2013; Ahmad and Thorpe, 2020). Thus, our application of visual affective discourse analysis does not disregard the power of discourse, but rather this methodological approach combined with thematic analysis 'is an extension and an attempt to bring the bodies into research' (Pavlidis, Rodriguez Castro and Kennelly, 2020: 5). 
As feminist scholars we acknowledge that our analysis was mediated through our own distinct positionalities and gazes (see Olive, 2013; Van Ingen, 2013). For example, there are limitations of our analysis as 'outsiders' to the debates of feminism in the Middle East, and as mostly white women (Authors B, C and D) working from academies in Australia. In saying that, we have a political commitment to destabilise the focus on Western and white women in mainstream feminist and sport scholarship, and advance anti-racism actions within the spaces we do our work (see Pavlidis and O'Brien, 2017; Pavlidis, Kennelly and Rodriguez Castro, 2020). In order to move beyond a mere acknowledgement of our positionalities, we also engaged in a dialogue embedded in critical feminist reflexivity in various stages of the analysis process. In these conversations we focused on the questions that Ahmed (2004a, 2004b) and Abu-Lughod (2013) pose in their work on how do we 'write against culture'? and 'what do emotions do?' We also corresponded with the CaiRoller in charge of communication to ask specific questions on how the team understood and constructed their Instagram page in order to address the limitations of discussing only representation in visual discourse analysis, as identified in previous work (Pavlidis, Rodriguez Castro and Kennelly, 2020).

As a result of these dialogues, the thematic analysis of the interviews and the visual discourse, we grouped findings into three key themes for discussion: 'embodied toughness', the CaiRollers constructions of 'sisterhood', and the team's concerns around 'transnationalism and legitimacy'. The images presented in this paper are Instagram posts that speak to each of these emerging themes. These images are reproduced with permission from the CaiRollers. Written consent was provided by the CaiRoller in charge of communications in 2020, following consultation with the team. Individuals interviewed also provided written consent for the use of interview data in this research. In addition, the final draft of this article was emailed to the CaiRollers for additional consent. League members were invited to read our work and the research team submitted the article once the CaiRollers had provided written support. 


\section{Findings}

\section{Embodied toughness}

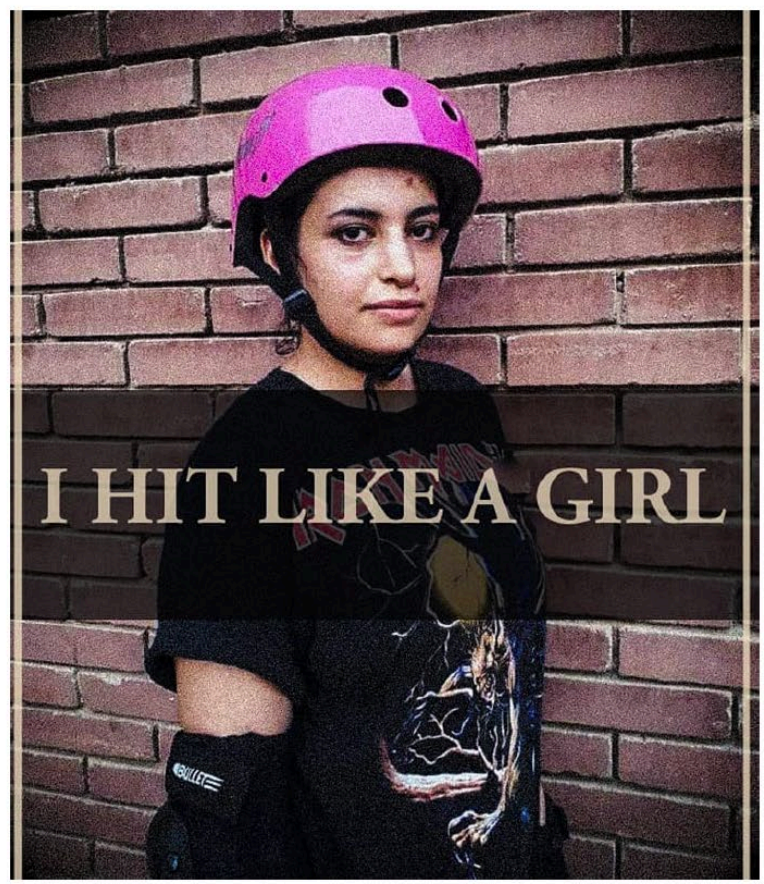

Figure I. Instagram post from March 2019, Instagram caption: I Hit Like a Girl! $\boldsymbol{C}_{\mathbf{0}} \boldsymbol{G}_{\mathbf{0}}$ Note: The caption continues: To Experience Roller Derby Live, Visit This Link: https://www.facebook.com/ events/510903 I42770883/ \#CaiRollers \#cairo \#egypt \#egyptian \#egyptiangirl \#sports \#egypte \#cairolife \#rollerderby \#rollerderbygirls \#rollerderbylife \#rollerskating \#rollerderbylove \#rollerderbytraining \#practice \#practiceeveryday \#rollerderbyofinstagram \#rollerderbyreferee \#rollerderbyproblems \#rollerderbyphotography \#womensupportwomen \#women \#womeninsports \#womenofegypt \#rollerderbyfitness.

The desire to be tough is found across cultures in roller derby, where the women involved articulate what they understand as a connection between playing roller derby and being viewed as 'badass'/strong woman (see for example Finley's (2010) articulation of 'pariah' identities made possible through derby). Through this desire, women in derby experience their bodies as strong, which is often one of the primary attractions of the sport (Pavlidis and Fullagar, 2014a). Figure 1 uses the phrase, 'I hit like a girl', which is commonly used across cultures by women to reclaim empowerment and to challenge men and boys who think that to be 'like a girl' is somehow 'less than' or derogatory. This phrase is foregrounded, with a skater in derby attire behind the text, with cuts and bruises on her face and a serious expression. The image shows this skater as tough and feminine and this idea is emphasised at various times across the CaiRollers' Instagram feed (for example, 31 March 2019; 4 April 2019; 16 May 2019).

Embodying toughness and strength was a source of pride for the CaiRollers, as interview Respondent 2 explained:

Roller derby is great fun...It's a tough sport. That toughness gives me a sense of pride. To play, you need to be daring and fearless. To try, and try again and again. To take the hits and falls, to brush off the pain and get back up and go at it again. To me that is strength and courage, qualities I admire and aspire to have. 
The affects associated with pride and toughness translated into values and aspirations for the skaters as individuals, but also 'as women', and Middle Eastern women who use roller derby as a way to 'write against culture' and support themselves to embody qualities they desired. As Respondent 2 stated: '[roller derby] defies the mindset that women are fragile and delicate and don't play sports. Roller derby is a rough contact sport and the women playing it show how tough and resilient they are. Not easily broken'. These responses denote a relationship between toughness and roller derby as a form of strength to deny victimisation and deficit constructions (Amara 2012; Burnett 2015; Dosekun 2015; Thorpe 2020; Thorpe and Ahmad 2015).

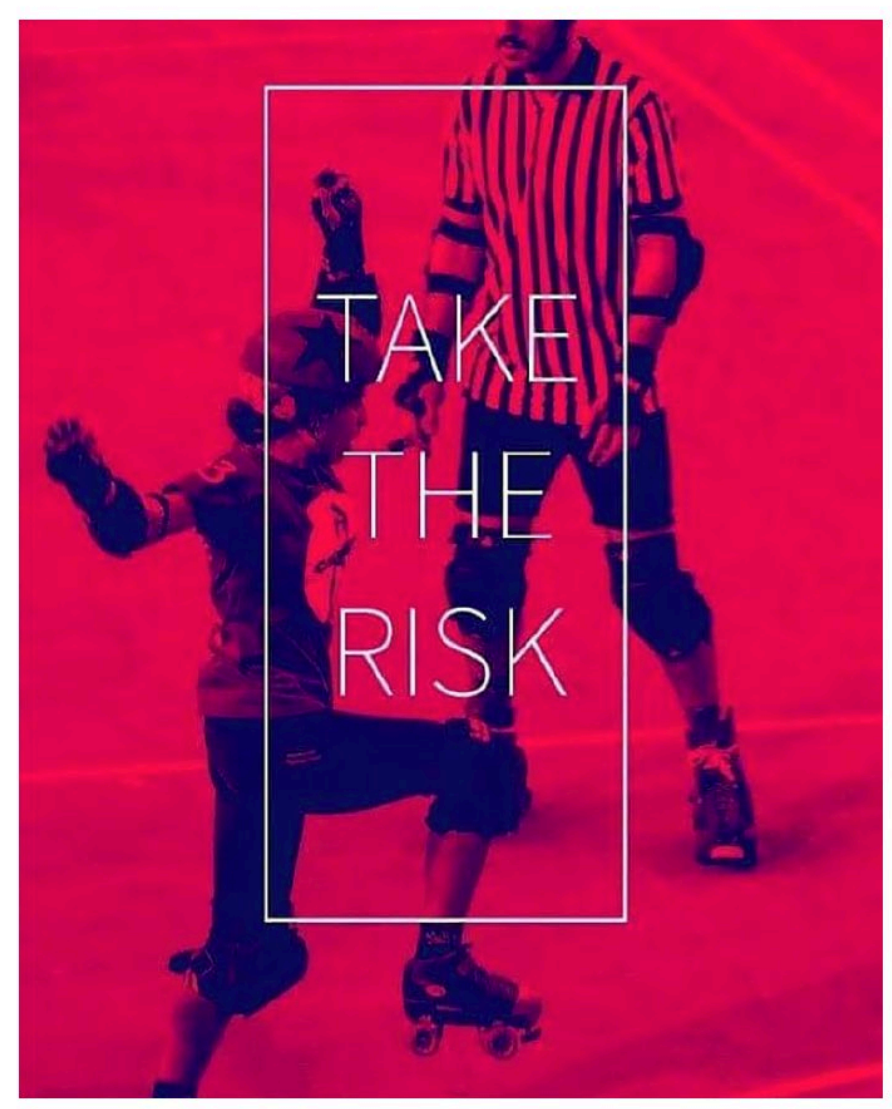

Figure 2. Instagram post from February 2018, Instagram caption: Take The Risk. Note: \#CaiRollers \#rollerderby \#rollerskating \#roller \#womeninsports \#sports.

For the derby players in Cairo, their performances of toughness were also experienced through 'fear' and risk. Figure 2 shows a skater mid-motion on the track, her arms in the air, with a referee in the background and text that reads, 'take the risk'. The photo is saturated in red, associating the image with blood (Figure 1 also features blood) and 'danger'. Here the CaiRollers acknowledge that fear is an emotion they experience through roller derby, but that they are able to work through that fear, reinforcing their toughness and strength. Respondent 1 noted: 
I think that kind of mentality goes into your life when you're not scared of the bad stuff. I think when you're in derby and you fall and you just want to get back up again right away. I think these things... somehow change your mentality of how you perceive things in general. So I think, yeah, that's one of the ways derby makes you tougher in life, not just in the sport itself, but in general.

Hence, the 'toughness' embodied by players served a purpose beyond their individual enjoyment. For example, players explained how through roller derby, they resisted structures of Egypt's 'conservative society'. Respondent 1 explained how Egyptian team members educated 'expats' on how to be safe in the local context where sexual harassment against women is common:

... we're sort of a conservative society, for better or worse. I guess the outfits of derby that are worn internationally would cause us problems, not because of scarves [head scarves] but because of just that harassment. So yeah, when we have expats, unfortunately we have to tell them to be careful and everything, just for their own safety and stuff. But generally, we wear what we want to wear...

Further, Nour, a CaiRoller interviewed in 2014 (in Grira, 2014, n.p.) recounted how roller derby training equipped her to be part of the anti-harassment movement at the Tahrir Square protests during the uprisings:

A few months after we first formed our team, I went to protest on Tahrir Square. Most people have heard about all of the instances of sexual assault and rape that took place there, often hidden in the chaos of the crowd. When I went to Tahrir that time, I felt much for [sic] confident because I knew that I could defend myself against assault... Later, I even joined the anti-harassment brigades that started patrolling the protests. Roller derby helps women gain confidence in a society plagued by harassment of women. It's not just a sport.

Thus, the embodied and affective politics of the CaiRollers that mobilise through roller derby - the skater's embodiment of 'toughness' which permeates their Instagram posts- has a purpose beyond the track in the way the team members care for each other and participate in Egypt's resistance movements. As fear leaps across bodies in specific everyday contexts and socio-historical moments of resistance in Egypt, the CaiRollers mobilise care-full strength.

\section{The CaiRollers 'sisterhood'}

We found that for the CaiRollers affective politics of toughness and strength were also coupled with collective affects of love through belonging to a sport for women with a feminist ethos. Respondent 1 noted, 'it's empowering' before elaborating:

.... Also, the feminist aspect, definitely, that well, I love the people, different body types or different backgrounds or different everything.... Even if you're like a former ballerina, you gain muscles or you toughen up because of the game itself... It grows out of love. It's not drilled into you, and at the same time I love the game. Every body type has its advantage. So if you're a larger person or tall or stuff, you have your advantages. If you're smaller or thinner you have your advantages...

The embodiment of the feminist ethos and their involvement in derby helped team members navigate societal pressures regarding sportswomen's body image and other challenges in their personal lives. 


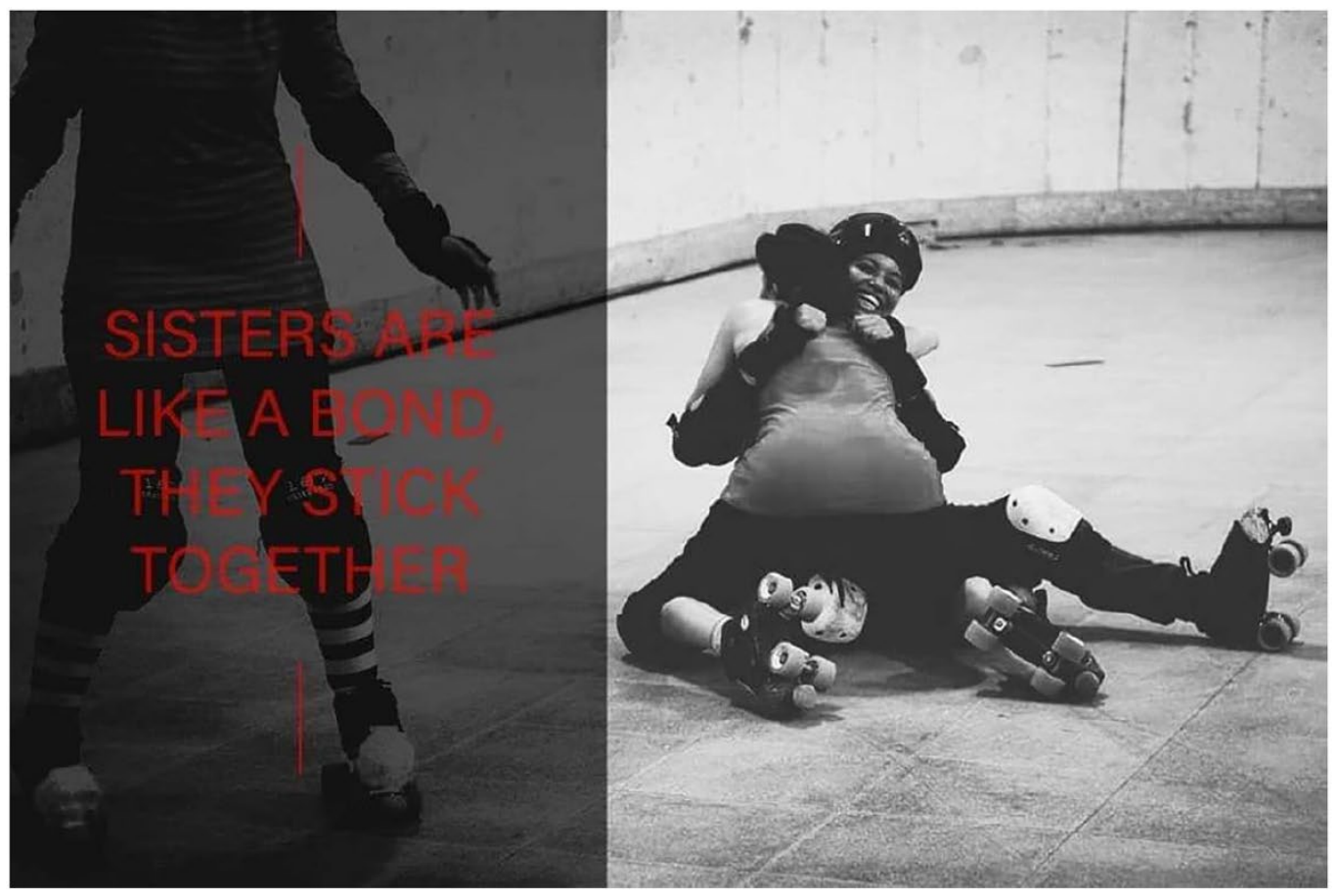

Figure 3. Instagram post from March 2019, Instagram caption: sisterhood!

Note: \#CaiRollers \#cairo \#egypt \#egyptian \#egyptiangirl \#sports \#egypte \#cairolife \#rollerderby \#rollerderbygirls \#rollerderbylife \#rollerskating \#rollerderbylove \#rollerderbytraining \#practice \#practiceeveryday \#rollerderbyofinstagram \#rollerderbyreferee \#rollerderbyproblems \#rollerderbyphotography \#womensupportwomen \#women \#womeninsports \#womenofegypt \#rollerderbyfitness.

Notably, the feminist ethos of the CaiRollers transgressed feminist debates on identity politics through a focus on embodied and affective dimensions of 'sisterhood'. In Figure 3, two players embrace each other during a training session in what appears to be the moment after one fell. The associated quote reads 'sisters are like a bond, they stick together' and the caption reads 'sisterhood', which was a term used in the interviews often. Respondent 3 elaborated on what the 'sisterhood' meant for her:

We are an all-female Egyptian team aiming to empower women in all paths of life through this amazing sport ... the sisterhood we have among the team and how she can add up to every member of the team .. unconditional love and strong support. The recurrence of 'love' in the team member's description of their 'sisterhood' demonstrates the 'pragmatic force' of this emotion in mobilising a collective feminist ethos in their own terms (see Abu-Lughod, 1991: 15). Indeed, the CaiRollers sisterhood resonates with the findings of Biagini (2020) on post-revolutionary Egypt and the 'Muslim Sisterhood' movement where feminist subjectivities and the adoption of feminist practices based on women's experiences are evident, without necessarily a self-identification as feminists. 


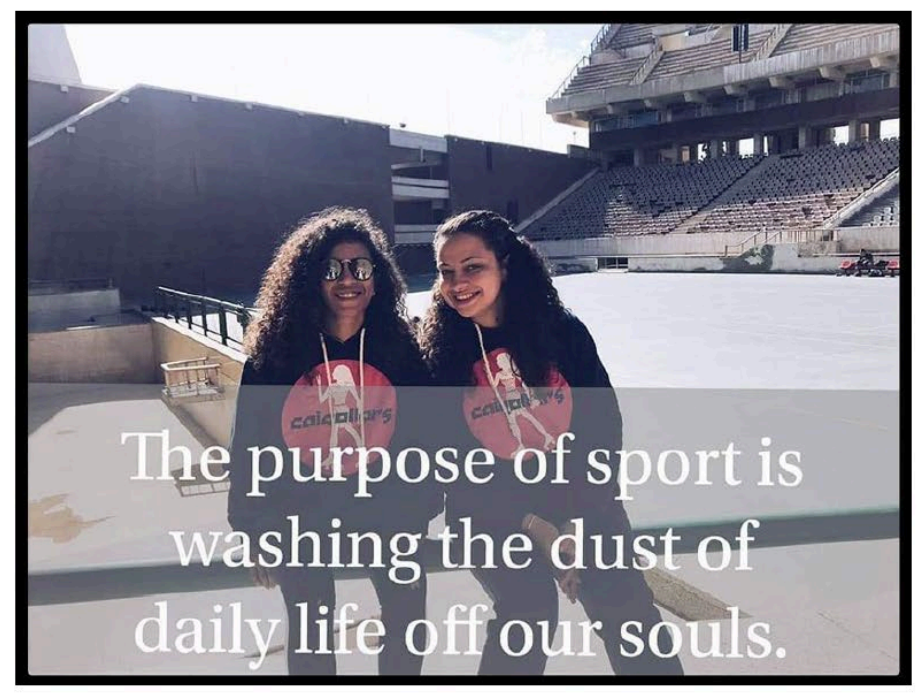

Figure 4. Instagram post from February 2018, Instagram caption: the purpose of sport is washing the dust of daily life off our souls!

Note: \#CaiRollers \#rollerderby \#rollerskating \#roller \#womeninsports \#sports.

The players also noted that the sisterhood bond transcended their encounters on the track, and that they supported each other in their personal lives as depicted in Figure 4. As Respondent 1 elaborated:

We support each other in our lives, everything like that. We travel together sometimes, even if it doesn't have to do with derby, but it's all team building... So we're all just a big team, we are... friends I guess. But it's all built on the game. We don't see competitiveness. I personally, I don't think, I haven't experienced it. We just want to grow together as a team. I think this is one of the... beautiful things about the sport.

Thus, the sport and the team were depicted as a medium to embody their friendships based on care for each other. Their Instagram posts captured how they help each other stretch (March 22 2018) and share food and outings as a team (June 3 2018; May 23 2018; September 15 2018; November 18 and 26 2018). Together these affects of love speak to how 'sticky emotions' and embodied bonds of 'sticking together' on the track are entangled in a 'sisterhood' that transcends the sport and constructs gender politics on their own terms (see Ahmed, 2004a).

The affects that mobilised beyond the track were also evidenced in the CaiRollers relationships with their families. In the interviews, respondents noted how their involvement in derby led them to negotiate with family members and other structures of society. For instance, Respondent 2 said:

As a working mother, would I be able to commit and make it to every practice? Would my husband approve? How will I manage buying my skates? Thankfully, now, a year and a half later, my concerns are put to rest. I am dedicated to make the time for practice. My parents and husband are supportive and watch the kids while I'm at practice.

In contrast, other players, such as Respondent 1 were able to use their involvement to invite more family members to join and grow the team: 
Then when I was going for the new season I told my family. Then my cousins, who had also seen the film ["Whip It"], found it really interesting... The three of us went and we're still playing there. So it's a family affair even when we hang about. The first row was just our family.

The importance of derby as a 'family affair' also resonated with Respondent 3's accounts and many of their Instagram posts where their families are featured (22 March 2018; 13 October 2018; 3 June 2018). Respondent 3 said that her favourite Instagram posts:

Would be all the pictures from our Ramadan iftar every year, because it really means to us how we are connected not just in practice but even in this. It has been a tradition since year one, and comparing each year's photo with the past year. Seeing our family growing and having new members, husbands and kids, melts our hearts. The assertion of 'public piety' in Respondent 3's quote defies assumptions about choice and women's empowerment of 'secular liberal feminisms' (Abu-Lughod 2019: 39). The CaiRollers' families and communities' involvement in the team demonstrates how 'writing against culture' through affective politics mobilises change and debunks Orientalist perspectives 'of Arab citizens as unilaterally opposed to gender equality and women's empowerment because of Islam' (Glas and Alezander, 2020: 26; Abu-Lughod, 1998, 2019). Their actions and politics of love resonate with feminisms in the Middle East that have argued for centering the everyday experiences of Middle Eastern women in their own terms (Abu-Lughod, 1998, 2013; Altorki and El-Solh, 1988).

\section{Legitimacy and transnationalism: institutional politics, structural change and affects}

It is clear that roller derby is a practice that embodies toughness and is entangled in a range of affective and political practices (e.g. love) that transcend the track. Storying the lived, everyday experience of the CaiRollers is demonstrative of how 'the impressions we have of others, and the impressions left by others are shaped by histories that stick, at the same time as they generate the surfaces and boundaries that allow bodies to appear in the present' (Ahmed, 2004b: 39). The CaiRollers have clearly found love and acceptance within their own ranks, yet gaining legitimacy with external audiences has proven somewhat intractable. Hence, the theme 'legitimacy and transnationalism' focuses on the CaiRollers' contrary experiences of 'getting taken seriously' (Breeze, 2014: 36). They have succeeded in being embraced by the international roller derby community, yet have encountered obstacles to gaining acceptance with a domestic (Egyptian) audience.

The team receives extensive support and recognition from outside Egypt. For example, the international derby community has supported the CaiRollers with donations of skating equipment and the team have organised bouts or training in Abu Dhabi, France and Amsterdam. Respondent 1 described the connections the CaiRollers have established with skaters from around the world as 'one of the best aspects' of derby. Shared connection is privileged over competition: 'they just tell us, "I'm from this team from this country and I would love to see you. And if you can guide me through your Cairo...." it becomes an instant friendship'. The 'love' felt within the transnational roller derby community is demonstrative of the crucial work affects do, wherein the very effect of collectivity can be described 'as "felt" as well as imagined and mediated' (Ahmed, 2004b: 39). While the CaiRollers are recognised within the international roller derby community, their recognition in Egypt is entangled within broader questions around 
the legitimacy of roller derby as a sport, as well as the place of women in sport in the Egyptian context.

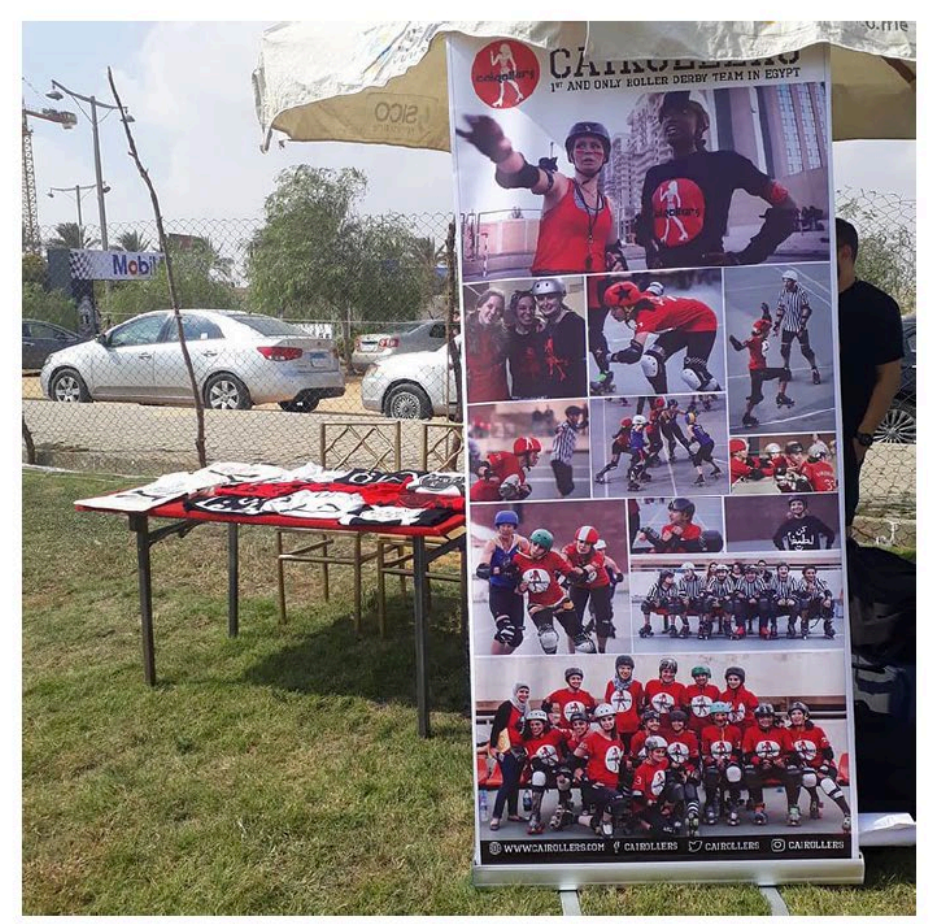

Figure 5. Instagram post from October 2018, Instagram caption: Happening now. Note: \#bikerzoneexpandshow @bikerzone_egypt.

The CaiRollers efforts to build 'legitimacy' range from work on digital platforms (i.e., website and active social media accounts), through to employing consistent and recognisable branding (e.g., the CaiRollers logo, 'colour scheme' (red and black), and merchandise), and their determination to improve their performance by engaging international coaches, running bootcamps and overseas training camps, and securing bouts with teams from other countries. The Instagram image in Figure 5 shows the CaiRollers' exhibit at an expo held in Cairo for outdoor, adventure, and extreme sports, where they staged roller derby demonstrations to raise awareness of their sport. These branding and recruitment strategies are arguably familiar to community sport clubs around the globe. Yet despite their efforts, Respondent 2 noted that the CaiRollers have experienced 'high turnover', and after eight years their league remains: 'the first and only roller derby team in Egypt' (CaiRollers n.d.). Through their recruitment efforts the CaiRollers have successfully endured, but they have not experienced significant growth in membership or domestic audiences, with Respondent 1 describing how the team is 'more connected to the outside leagues of derby than the inside national side of sports' in Egypt.

Notably, the CaiRollers consider social media a critical tool in their efforts to speak both to an Egyptian audience for the purposes of recruitment and the broader international roller derby community, as summed up by Respondent 3: 
we use it [social media] mainly to show the derby world what are we up to, and also to attract girls to join our team .. and of course [as] a platform to announce about our bout so people can come along and support us and learn more about roller derby.

However, Respondent 3 acknowledged that the account's actual audience were 'mainly our friends and family and other derby sisters around the world... and Egyptian fans but soo, soo [sic] little to be honest. This is sad I know'. When Respondent 3 was asked why she felt there was limited interest within Egypt she attributed it to the dominance of football, lack of understanding (i.e., as to what roller derby is), and the busyness of Egyptian lives. Respondent 2 also explained that gender discrimination in Egyptian culture creates obstacles: ' ...very few women [in Egypt] play sports, and even fewer play team sports. I can say that we, the CaiRollers skaters, are an anomaly'. Respondent 2 expounded on how 'old customs and traditions and mindsets' may hamper the CaiRollers' efforts to attract local players and audiences because: 'in the culture of the area, the idea of a grown up woman [playing sport] may be unacceptable to some people. And even if a woman is open to the idea, her family might disapprove'.

Alternatively, perhaps the challenges arise from roller derby itself, and its broader struggle to be taken seriously. As Respondent 2 described: 'most people [in Egypt] don't know what roller derby is. At all'. Derby's cultural heritage and 'ownership' (i.e., international governance, markets, forms of expression) are predominantly Western, and its typically womenonly nature are an inconsistent reversal of the 'normal' (comfortable) global domination of male sports.

In this section we aimed to narrate a paradox in the CaiRollers efforts to be taken seriously: their efforts to gain legitimacy have seen them work hard to build international connections, yet these efforts have not had the same effect for local audiences. In 'writing against culture' the aim is not to offer a resolution of highly complex and often contradictory power relations but rather to make visible the work that affects 'do'.

\section{Conclusion}

Through narrating the affective dimensions, and local and transnational affective politics of the CaiRollers we have attempted to 'write against culture' and work 'against generalization' and 'othering' (Abu-Lughod, 2008: 19) asking: What do physical practices such as roller derby 'do' in e/affecting and mobilising change? The embodied and geographically contingent experiences of roller derby in Egypt bring to the fore the ways that the sport transcends the track and becomes entangled in political movements, local gender politics, transnational mobilities and questions of legitimacy and sport. Through our conversations with team members and affective visual discourse analysis we have found that roller derby is a social, cultural, and political practice in which desires for risk, toughness and strength, and collective e/affects of love and fear, and local and transnational (dis)encounters operate.

In this article we have demonstrated how the socio-political context in which the CaiRollers were founded, during the Arab Spring, is entangled with their feelings of toughness, risk and impact as they invade the (digital) (Ahmad, 2020: 169) sporting landscape of roller derby. On one hand, the CaiRollers sisterhood resonates with feminisms from the Middle East that have argued for the importance of decentering Western constructions of feminism and gender politics (Abu-Lughod, 1991, 1998, 2013; Altorki and El-Solh, 1988; Biagini, 2020). Public piety, roller derby as a 'family affair', and the DIY feminist ethos of the team speaks to gender politics that are being enacted from the lives of the skaters, by the skaters and for the 
team on their own terms. At the same time, through a focus on the everyday obstacles that the team has faced, we have found that whilst the CaiRollers have on the surface a legitimate and transnational collectivity as 'felt', imagined and mediated, they must still work hard within Egypt to capture, educate, and retain domestic audiences, players, officials and sponsors.

Roller derby in Egypt provides a space for belonging, love, and friendship, embedded in a sport practice that is tough, rough and risky. Through roller derby the CaiRollers have had the opportunity to represent themselves via Instagram as fearless risk-takers and to claim space nationally and internationally. But more than this, they have embodied the affects of pushing their bodies, training like athletes, and enjoying the pleasures of intense team contact sport. These affects are not commonly experienced by Egyptian women as team sports for women are still in development, yet through roller derby and its more-than-sport articulations, the CaiRollers face fears - and make it known to a broader public that they are taking risks. In this way they can be viewed as 'space invaders' (Puwar, 2004: 8). This conceptualisation of affect and emotion as having material (and psychic) effects on the world can be understood as another strategy of 'writing against culture', cutting through Abu-Lughod's three original strategies. Affect and emotion create connections, and are implicated in discourses and practices in specific cultural contexts. The notion of affect as political and world-making helps us to see the ways that gendered cultures, like roller derby, can support situated politics of emotion that can mobilise change.

\section{Acknowledgements}

We would like to thank the CaiRollers for their time and enthusiasm during the interviews conducted for this article.

\section{Funding}

The author(s) disclosed receipt of the following financial support for the research, authorship, and/or publication of this article: Part of this work was supported by the Australian Research Council(grant number DE180100377). 


\section{References}

Abu-Lughod L (1991) Writing against culture. In RC Fox (pp. 137-54). Recapturing Anthropology: Working in the Present. Santa Fe: School of American Research Press

Abu-Lughod L (1998) Remaking Women: Feminism and Modernity in the Middle East. Princeton. New Jersey: Princeton University Press.

Abu-Lughod, L (2008) Writing Women's Worlds. Berkeley: University of California Press.

Abu-Lughod L (2013) Do Muslim Women Need Saving? Cambridge: Harvard University Press.

Abu-Lughod L (2019) On teaching gender and Islam in the Middle East. JadMag: The Pedagogy Edition. Available at:

https://tadweenpublishing.com/collections/jadmag/products/jadmag-issue-7-2-pedagogy$\underline{2019 .}$

Ahmad N (2020) The digital lives of Muslim sportswomen: Navigating the spaces of sport, culture, and social media. Available at: http://researchcommons.waikato.ac.nz/

Ahmad N and Thorpe H (2020) Muslim Sportswomen as Digital Space Invaders: Hashtag Politics and Everyday Visibilities. Communication \& Sport. 8: 668 - 691.

Ahmed S (2004a) The Cultural Politics of Emotion. Edinburgh: Edinburgh University Press.

Ahmed S (2004b) Collective feelings: Or, the impressions left by others. Theory, Culture \& Society 21(2): 25-42.

Altorki S and El-Solh CW (1988) Arab Women in the Field: Studying Your Own Society. Syracuse: Syracuse University Press.

Amara M (2012) Sport, Politics and Society in the Arab World. London: Palgrave Macmillan.

Beaver TD (2012) "By the skaters, for the skaters" The DIY ethos of the roller derby revival. Journal of Sport and Social Issues 36(1): 25-49.

Biagini E (2020) Islamist women's feminist subjectivities in (r)evolution: the Egyptian Muslim sisterhood in the aftermath of the Arab uprisings. International Feminist Journal of Politics 22(3): 382-402.

Breeze M (2013) Analysing 'seriousness' in roller derby: Speaking critically with the serious leisure perspective. Sociological Research Online 18: 1-13 
Breeze M (2014) Just a big sexy joke?: Getting taken seriously in women's roller derby. Unpublished PhD Thesis, The University of Edinburgh, UK. Available at: http://hdl.handle.net/1842/9845.

Burnett C (2015) Assessing the sociology of sport: On sport for development and peace. International Review for the Sociology of Sport 50(4-5): 385-390.

CaiRollers. (n.d.) 'About' [webpage]. Available at: https://www.cairollers.com/about/

Cardoso Brown LEC (2018) Post-colonial Feminism, Black feminism and sport. In L Mansfield, J Caudwell, B Wheaton, and B Watson (Eds.), The Palgrave Handbook of Feminism and Sport, Leisure and Physical Education (pp. 479-495). London: Palgrave Macmillan UK.

Carlson J (2010) The Female signifiant in all-women's amateur roller derby. Sociology of Sport Journal 27(4): 428-440.

Dosekun S (2015) For Western girls only? Feminist Media Studies 15(6): 960-975.

Egyptian Streets (2014, June 20) CaiRollers: Empowering women one skater at a time. Available at: https://egyptianstreets.com/2014/06/20/cairollers-empowering-women-one-skater-ata-time/

Finley NJ (2010) Skating femininity: Gender manoeuvring in women's roller derby. Journal of Contemporary Ethnography 39(4): 359-387.

Gbadamosi N (2017, January 22) The girls spearheading roller derby's revival in Egypt. CNN. Available at: https://edition.cnn.com/2017/01/18/africa/egypt-roller-derby$\underline{\text { revival/index.html }}$

Glas S and Alexander A (2020) Explaining support for Muslim feminism in the Arab Middle East and North Africa. Gender \& Society 34(3): 437-466.

Grira S (2014, 14 August) Roller derby: Helping Egyptian women stand up for themselves. The Observers. Available at: https://observers.france24.com/en/20140814-roller-derby-egyptwomen-cairollers.

Leeuwen TV and Jewitt C (2001) Handbook of Visual Analysis. London: Sage.

Lutz CA and Abu-Lughod, L (Eds.) (1990) Language and the Politics of Emotion. Cambridge: Cambridge University Press.

Markula P (2006) Deleuze and the Body Without Organs: Disreading the Fit Feminine Identity. Journal of Sport \& Social Issues. 30(1): 29-44. 
Mohamed E, Mahdi W and Dabashi H (2020) The aesthetics of dissent: Culture and politics of transformation in the Arab world. International Journal of Cultural Studies 23(2): 141149.

Nouraie-Simone F (2014) On Shifting Ground: Muslim Women in the Global Era. New York: The Feminist Press at CUNY.

Olive R (2013) 'Making friends with the neighbours': Blogging as a research method. International Journal of Cultural Studies, 16(1), 71-84.

Pavlidis A and Fullagar S (2013) Becoming roller derby grrrls: Exploring the gendered play of affect in mediated sport cultures. International Review for the Sociology of Sport 48(6): 673-688.

Pavlidis A and Fullagar S (2014a). Sport, Gender and Power: The Rise of Roller Derby. Farnham: Ashgate Publishing, Ltd.

Pavlidis A and Fullagar S (2014b). Women, sport and new media technologies: Derby Grrrls online. In A Bennett, B Robards B. (Eds.), Mediated youth cultures (pp. 165-181). London. Palgrave Macmillan.

Pavlidis A and Fullagar S (2015). The pain and pleasure of roller derby: Thinking through affect and subjectification. International Journal of Cultural Studies 18(5): 483-499.

Pavlidis A and O'Brien W (2017) Sport and feminism in China: On the possibilities of conceiving roller derby as a feminist intervention. Journal of Sociology 53(3): 704-719.

Pavlidis A, Kennelly M and Rodriguez Castro L (2020) White women smiling? Media representations of women at the 2018 Commonwealth Games. Sociology of Sport Journal 37(1): 36-46.

Pavlidis A, Rodriguez Castro L and Kennelly M (2020) Shame, pain and fame: Sportswomen losing in Australia's mainstream media reporting. Sport in Society. https://doi.org/10.1080/17430437.2020.1777101.

Puwar N (2004) Space Invaders: Race, Gender and Bodies Out of Place. Berg: Oxford.

Ratna A (2018) Not just merely different: Travelling theories, postfeminism and the racialised politics of women of color. Sociology of Sport Journal 35(3): 197-206.

Rose G (2001) Visual Methodologies: An Introduction to the Interpretation of Visual Materials. London: Sage.

Said EW (1978) Orientalism. New York: Pantheon Books. 
Samie SF and Toffoletti K (2018) Postfeminist paradoxes and cultural difference: Unpacking media representations of American Muslim sportswomen Ibtihaj and Dalilah Muhammad. In K Toffoletti, H. Thorpe, J Francombe-Webb (Eds.), New Sporting Femininities: Embodied Politics in Postfeminist Times (pp. 87-109). Basingstoke: Palgrave Macmillan.

St Pierre EA (2001) Coming to theory: Finding Foucault and Deleuze. In K Weiler (Ed.), Feminist Engagements: Reading Resisisting, and Revisioning Male Theorists in Education and Cultural Studies (pp.141-164). London: Routledge.

Thorpe H (2020) Informal sports for youth recovery: Grassroots strategies in conflict and disaster geographies. Journal of Youth Studies. https://doi.org/10.1080/13676261.2020.1763936.

Thorpe H and Ahmad N (2015) Youth, action sports and political agency in the Middle East: Lessons from a grassroots parkour group in Gaza. International Review for the Sociology of Sport 50(6): 678-704.

Toffoletti K and Thorpe H (2020) Bodies, gender, and digital affect in fitspiration media. Feminist Media Studies. https://doi.org/10.1080/14680777.2020.1713841.

Toffoletti K and Palmer C (2017) New approaches for studies of Muslim women and sport. International Review for the Sociology of Sport 52(2): 146-163.

United Nations Women, Arab States/North Africa (2018) Take five: "Roller derby and sport, in general, is empowering for women", July 2. Available at: http://arabstates.unwomen.org/en/news/stories/2018/7/roller-derby

Van Ingen C (2013) Seeing what frames our seeing": Seeking histories on early black female boxers. Journal of Sport History 40(1): 93-110.

Walsh D (2017, 28 December) Bump, Tumble, Go Faster! In Egypt, Roller Derby Is Real Life. The New York Times. Available at: https://www.nytimes.com/2017/12/28/world/middleeast/cairo-roller-derby-women.html.

Wetherell, M (2013) Affect and discourse - What's the problem? From affect as excess to affective/discursive practice. Subjectivity 6(4): 349-368. 